\title{
THREE-DIMENSIONAL ANALYSIS OF NEGATIVE WATER PRESSURE PROPAGATION FOR PUMPING WELL WITH EFFECTS ON GROUNDWATER FLOW
}

\author{
Atsushi TSUTSUMI ${ }^{1}$, Kenji JINNO², Tetsuji OZAKI 3 , Hisao NAKAYAMA4 \\ and Ronny BERNDTSSON ${ }^{5}$ \\ ${ }^{1}$ Member of JSCE, SG Technical Consultant Corporation (Aoba 1-19-22, Higashi-ku, Fukuoka 813-0025, Japan) \\ E-mail: a_tutumi@hiz.bbiq.jp \\ ${ }^{2}$ Member of JSCE, Professor Emeritus, Kyushu University \\ (Izumigaoka 1-4-5, Munakata City, Fukuoka 811-4142, Japan) \\ E-mail: kj55jp@ybb.ne.jp \\ ${ }^{3}$ Member of JSCE, Asahi-Techno Corporation (Hirai 5-11-8, Edogawa-ku, Tokyo 132-0035, Japan) \\ E-mail: ozakit02@gmail.com \\ ${ }^{4}$ Member of JSCE, Siesta Club Corporation (Shin-tateiwa 9-8, Iizuka City, Fukuoka 820-0004, Japan) \\ E-mail: hisat.nakayama@gmail.com \\ 5Professor, Lund University, Sweden (Box 118, 22100 Lund, Sweden) \\ E-mail: Ronny.Berndtsson@tvrl.lth.se
}

\begin{abstract}
The application of negative water pressure by vacuum in pumping wells results in a drawdown of groundwater table at excavation sites. Due to the vacuum, negative water pressure will propagate around the pumping well. As a result, a large potential gradient is induced and groundwater drawdown is enhanced. In the present paper, a numerical model for three-dimensional unconfined groundwater flow towards a pumping well (Deep Well, hereafter DW) is developed and evaluated. First, the accuracy of the model is confirmed by comparing the pumping rates at steady state given by the DW formula. Second, the numerical model for negative water pressure (hereafter, NWP) is described. The model can be used in practical applications together with the water balance equation to describe groundwater inflow and pumping rate in a pumping well so that time-dependent boundary conditions are considered with the three-dimensional groundwater flow equation. How the saturated-negative pressure zone develops around the pumping well is shown. Detailed relationships between water level, pumping rate, and propagation of the negative pressure zone are described and analyzed. The analyses show that the model results can be used to operate air and water pumps more efficiently for water balance and groundwater drawdown.
\end{abstract}

Key Words : groundwater drawdown, vacuum pump, 3-dimensional groundwater numerical simulation, propagation of negative water pressure

\section{INTRODUCTION}

Prior to excavation at building sites, it is necessary to draw down the groundwater table to the target level of the construction. The well point method (WP), deep well method (DW), and shallow sump method (SS) are commonly used techniques for this, considering site-specific conditions. Recently, a new method using both air vacuum pump and water pump has been developed. The method creates a large gradient of piezometric head around the pumping well. As a result, groundwater drawdown is efficiently achieved by vacuum in the well. Hereafter, we refer to this method as NWP (Negative Water Pressure method). There are several interesting characteristics of NWP. An air vacuum and a water pump operate simultaneously in the well to create large negative water pressure. Accordingly, the piezometric head, which is the summation of water pressure head, air pressure, and elevation, becomes negative in and around the pumping well. Due to the extremely low piezometric head, the NWP water 


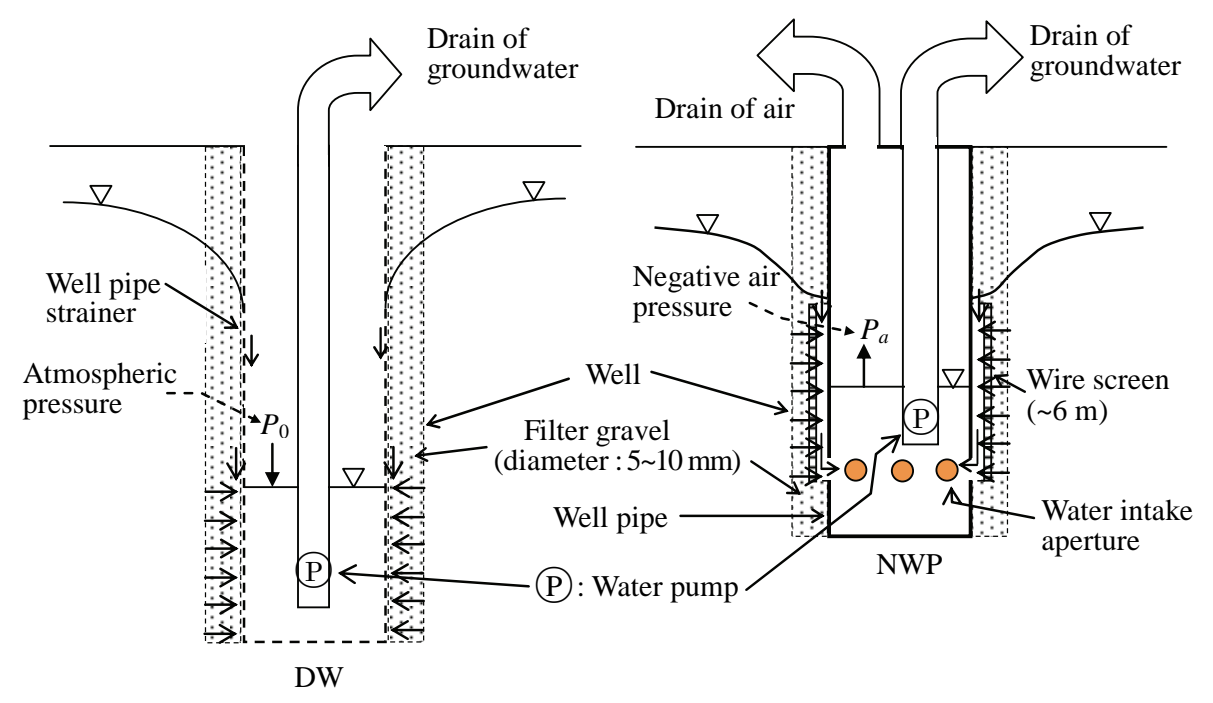

Fig. 1 Comparison of NWP and DW structures.

intake aperture can be placed close to the excavation level. Further, the time required to lower groundwater to the target level is shorter, compared to other methods. The number of NWP applications is rapidly increasing due to the efficiency of this method. For example, NWP was employed at the foundation construction of a water gate for tsunami protection near an estuary ${ }^{1)}$ and at the excavation work of a subway connection to the airport at Sendai, Japan ${ }^{2)}$. Besides, NWP is often used to vacuum groundwater pollutants such as volatile organic carbons and oil to remediate polluted soil and groundwater ${ }^{3), 4)}$. The studies by Nakagawa et al. ${ }^{5)}$ for a cross section and Hosokawa et al. ${ }^{6)}$ for a cylindrical domain demonstrated that negative water pressure zones around NWP wells develop in a clear way. However, to better understand the characteristics of three-dimensional groundwater flow around the NWP zone, more detailed analyses are necessary. Thus, the paper develops a water balance equation for a NWP well to calculate water inflow rate and variations of water level in the well. Then, the change in piezometric head in the well is used as boundary condition in the groundwater flow equation. It is shown that coupling water balance and groundwater equations is important to better understand the effects of the NWP method. The paper is concluded by discussing the practical applications of the modeling results.

\section{PRINCIPLES OF THE NEGATIVE WA- TER PRESSURE METHOD (NWP)}

Figure 1 shows a comparison between the layouts of DW and NWP. In general, the upper part of DW is open to the atmosphere and groundwater flows into the well by gravitation through the well screen. For
NWP, the upper part is sealed by a cap and negative air pressure in the well is maintained by vacuum. Furthermore, the water pressure in the well is lowered even more by a groundwater drainage pump. As a result, the groundwater pressure in the vicinity of NWP becomes negative and a large piezometric gradient in the surrounding soil is developed. In this situation, a negative piezometric domain is formed around the well.

The principle of NWP differs from that of the vacuum deep well (VDW) method in that the NWP water intake aperture is located at the bottom part of the well. In the case of VDW, vacuum is applied along the entire well screen. The disadvantage of this, however, is that the vacuum pump may easily suck air in the unsaturated zone and thus the vacuum power may be significantly reduced.

As illustrated for the NWP, the $6 \mathrm{~m}$ long wire screen is usually set at the lower part of the well. The apparent permeability of the wire screen should be high compared to the original aquifer. The open space between the wire screen and well wall is $2 \sim 3$ $\mathrm{cm}$. Groundwater enters through this open space and then flows into the well through the water intake aperture. Filter gravel ranging from 5 to $10 \mathrm{~mm}$ in diameter is used to fill the outside of the wire screen similarly as for the DW. Since the permeability of the filter gravel and the open space is large, negative water pressure in the well can easily propagate to the surrounding aquifer area. As a result, a large potential gradient is created.

It should be noted, however, that the unsaturated air above the groundwater table may be sucked into the negative water pressure zone when the unsaturated region approaches the high- permeability domain. If air in the unsaturated region enters the NWP well, negative air pressure may weaken and decrease the piezometric head in the well. Thus, it is important 
to control air pressure around the well. This can be achieved by continuously managing the water balance, change in water level, and piezometric head in the NWP well by model simulations.

\section{THREE-DIMENSIONAL SATURATED -UNSATURATED FLOW EQUATION AND NWP PRINCIPLES}

\section{(1) Fundamental groundwater flow equation}

For three-dimensional groundwater analyses, the following equations are applied:

$$
\begin{aligned}
& \left(C_{w}+\eta \cdot S_{s}\right) \frac{\partial h}{\partial t}=-\frac{\partial u}{\partial x}-\frac{\partial v}{\partial y}-\frac{\partial w}{\partial z} \\
& u=-k(\theta) \frac{\partial h}{\partial x} \quad, \quad v=-k(\theta) \frac{\partial h}{\partial y} \\
& w=-k(\theta)\left(\frac{\partial h}{\partial z}+1\right)
\end{aligned}
$$

where the first is the continuity equation and the second is Darcy's equation extended to unsaturated flow. The relationship between the water pressure head $h$ and volumetric water content $\theta$ needs to be given to solve Eqn. (1). For this, the Van-Genuchten ${ }^{7)}$ model is applied:

$$
\begin{aligned}
& S_{e}=\frac{\theta-\theta_{r}}{\theta_{s}-\theta_{r}}=\frac{1}{\left(1+\alpha \cdot(|h|)^{n}\right)^{m}}, \quad m=1-1 / n \\
& C_{w}=\frac{\alpha \cdot m \cdot\left(\theta_{s}-\theta_{r}\right) \cdot S_{e}{ }^{1 / m} \cdot\left(1-S_{e}^{1 / m}\right)^{m}}{1-m} \\
& k=k_{s} \cdot S_{e}{ }^{1 / 2} \cdot\left\{1-\left(1-S_{e}{ }^{1 / m}\right)^{m}\right\}^{2}
\end{aligned}
$$

where $C_{w}$ is specific moisture capacity $\left(\mathrm{m}^{-1}\right) ; \eta$ is parameter, which takes 1 in saturated region and 0 in unsaturated region; $S_{s}$ is specific storage coefficient $\left(\mathrm{m}^{-1}\right) ; S_{e}$ is effective saturation ratio; $\theta_{s}$ is saturated volumetric water content; $\theta_{r}$ is residual volumetric water content; $k_{s}$ is saturated permeability (original permeability of soil in saturation); $h$ is water pressure head (m); $t$ is time $(\mathrm{s}) ;(u, v, w)$ is Darcy velocity components in $x, y$, and $\mathrm{z}$ directions $\left(\mathrm{m} \mathrm{s}^{-1}\right) ; \theta$ is volumetric water content; $k(\theta)$ is permeability dependent on volumetric water content $\left(\mathrm{m} \mathrm{s}^{-1}\right)$; and $(x$, $y, z)$ is Cartesian coordinates (m).

Note that the non-Darcy flow is not considered in

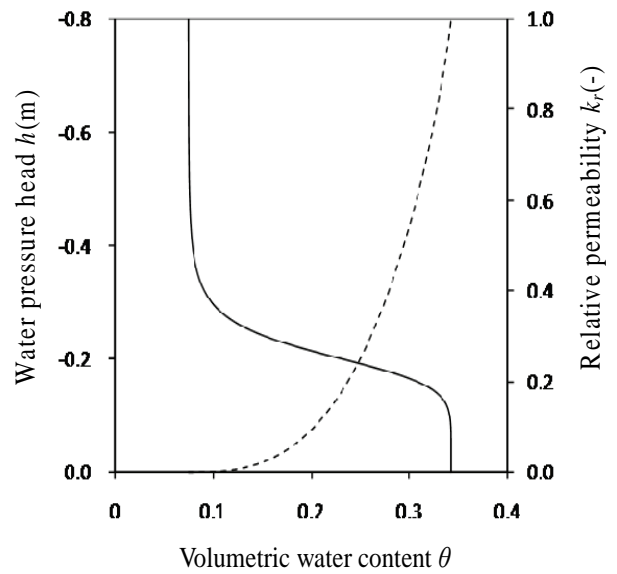

Fig. 2 Water retention curve used in the present simulation.

Table 1 Parameters used in the simulation ${ }^{8), 9)}$.

\begin{tabular}{c|c|c|c|c|c|c}
\hline & & \multicolumn{5}{|c}{ Parameters for unsaturated soil } \\
\cline { 3 - 7 }$S_{s}\left(\mathrm{~m}^{-1}\right)$ & $k_{s}\left(\mathrm{~m} \mathrm{~s}^{-1}\right)$ & $\begin{array}{c}\alpha \\
\left(\mathrm{m}^{-1}\right)\end{array}$ & $m$ & $n$ & $\theta_{s}$ & $\theta_{r}$ \\
\hline $1.0 \times 10^{-3}$ & $5.0 \times 10^{-5}$ & 4.91 & 0.86 & 7.14 & 0.34 & 0.075 \\
\hline
\end{tabular}

the present analyses. It is also assumed that the permeability is homogeneous and isotropic. The parameters $\alpha$ and $m$ (or $n$ ) are referred from soil properties shown in the soil catalogue No.4118 by Mualem ${ }^{8)}$. Figure 2 illustrates the water retention curve and relationship between the volumetric water content and relative permeability $k_{r}\left(=k / k_{s}\right)$ when the parameters in Table 1 are applied ${ }^{9)}$. Since we intend to visualize the propagation of negative water pressure in the saturated region around the pumping well for typical soil conditions, representative soil parameters are used.

(2) Relationship between air pressure $P_{a}$ and water pressure head $h$ at the water intake aperture

Figure 3 shows the relationship between the water level $h_{w}(t)$, air pressure $P_{a}(t)$, and water pressure head $h_{s}(t)$ at the aperture elevation after time $t$. Let $Z_{s}$ denote the elevation of aperture from the NWP well bottom. Then, the water pressure head $h_{s}(t)$ at the aperture becomes:

$$
h_{s}(t)=h_{w}(t)-Z_{s}+\frac{P_{a}(t)}{\rho_{w} \cdot g}
$$

The piezometric head $H_{s}(t)$ under air vacuum pressure $P_{a}(t)$ is: 


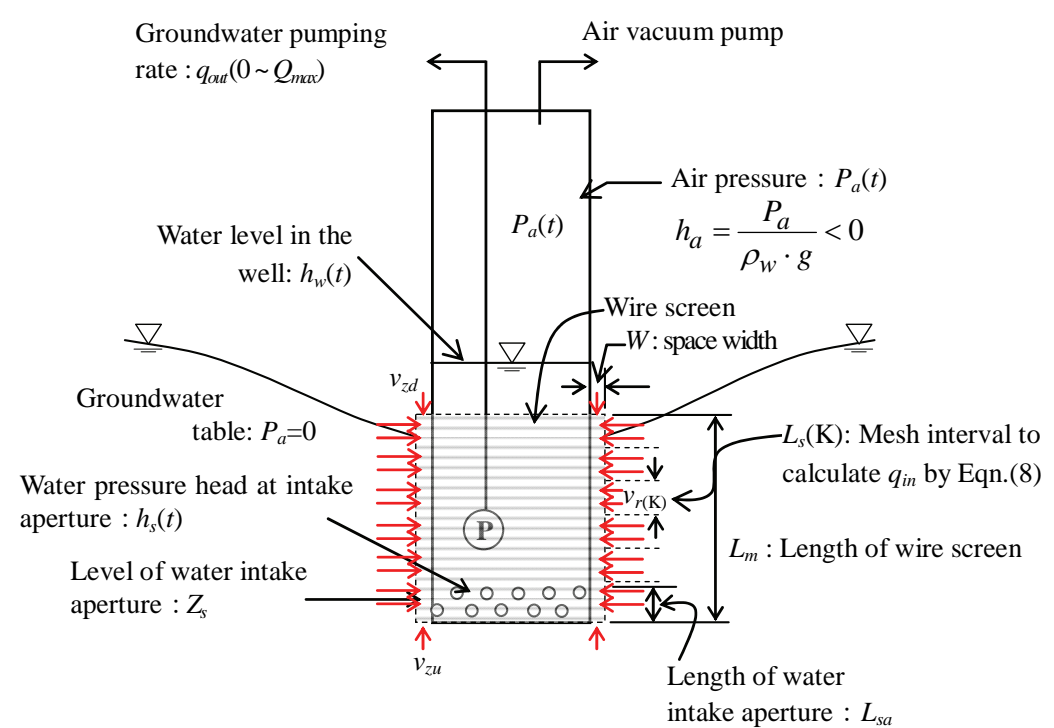

Fig. 3 Water level, air pressure, water pump, and water pressure head in NWP well.

$$
\begin{aligned}
H_{s}(t) & =h_{s}(t)+Z_{s} \\
& =\left[h_{w}(t)-Z_{s}+\frac{P_{a}(t)}{\rho_{w} \cdot g}\right]+Z_{s} \\
& =h_{w}(t)+\frac{P_{a}(t)}{\rho_{w} \cdot g}
\end{aligned}
$$

where $\rho_{w}$ is the density of water and $g$ is the gravity acceleration. It is obvious that $H_{s}(t)$ becomes smaller than $h_{w}(t)$ when $P_{a}(t)$ is negative.

\section{(3) Water balance equation, control of pumping rate, and vacuum pressure in the NWP well}

Equation (5) represents the water continuity in the well:

$$
A_{w} \frac{d h_{w}}{d t}=q_{\text {in }}-q_{\text {out }}
$$

where $A_{w}$ is cross-sectional area of the well, $q_{i n}$ is groundwater inflow rate into the well through the intake aperture, and $q_{\text {out }}$ is pumping rate.

Assuming that Darcy's law is applicable, the groundwater velocity components entering through the wire screen can be written as:

$$
\begin{aligned}
& v_{r}=-k_{a} \cdot \frac{\partial H(x, y, z, t)}{\partial r} \\
& v_{z}=-k_{a} \cdot \frac{\partial H(x, y, z, t)}{\partial z}
\end{aligned}
$$

where $v_{r}$ is the velocity component in the radial direction, $v_{z}$ represents the vertical component, and $H(x, y, z, t)$ is the piezometric head. The apparent permeability $k_{a}$ around the wire screen is set larger than in the original soil permeability. In general, this narrow zone around the pumping well supports the original soil from collapsing. The material in this zone is usually gravel or coarse sand larger than the original particle diameter. Also, the wire screen for the aperture taking groundwater has less resistance to the fluid flow. The purpose of the present study is to demonstrate that negative water pressure develops around this high-permeability zone under the effect of enhanced pressure by air vacuum pump. In the present simulation, the apparent permeability is set approximately two orders of magnitude larger than the permeability of the original soil. It is obvious that the extension of the negative pressure around the well depends on the air vacuum pressure and the apparent permeability.

Assuming that the groundwater inflow rate $q_{\text {in }}$ can be approximated by a cylindrical mesh:

$$
\begin{aligned}
q_{i n}= & \sum_{\mathrm{K}}\left[2 \pi \cdot\left(r_{w}+W\right) \cdot L_{s(\mathrm{~K})} \cdot v_{r_{(\mathrm{K})}}\right] \\
& +\pi \cdot\left(v_{z u}+v_{z d}\right) \cdot\left\{\left(r_{w}+W\right)^{2}-r_{w}{ }^{2}\right\}
\end{aligned}
$$

where $v_{r(\mathrm{~K})}$ is the radial velocity at vertical grid number $\mathrm{K}$ of the well, $r_{w}$ is the well radius, $W$ is the space width between wire screens and the exterior wall of well, $L_{s(\mathrm{~K})}$ is the K-th mesh interval to calculate $q_{i n}$ by Eqn.(8), and $v_{z u}$ and $v_{z d}$ represent the vertical velocity components in the upward and downward directions along the well, respectively. The change in water depth $h_{w}(t)$ in Eqn. (5) can be calculated if $q_{\text {in }}$ in Eqn. (8) and $q_{\text {out }}$ are given at every time step. It is obvious from Eqn. (4) that the piezometric head $H_{s}(t)$ changes corresponding to the changes in $h_{w}(t)$ and $P_{a}(t)$. Note that $P_{a}(t)$ is an operating variable to control the drawdown of 


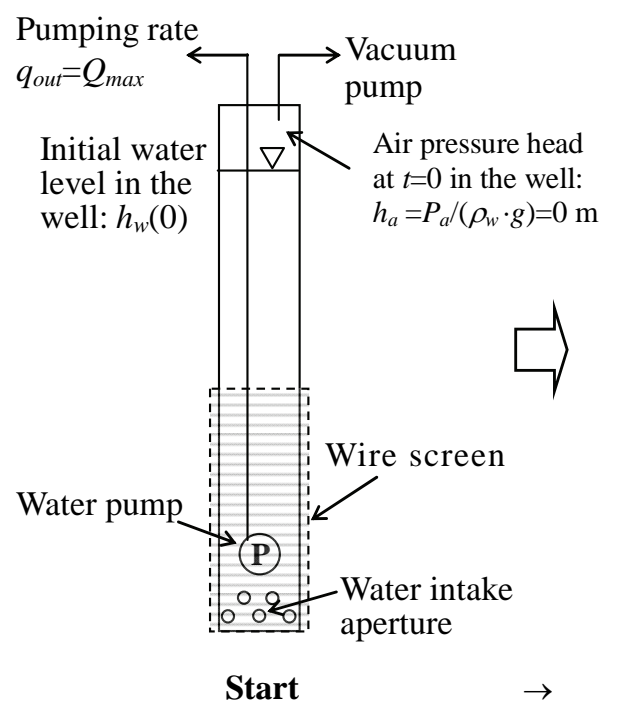

Fig. 4 Control of pumping rate $q_{\text {out }}$ and air pressure $P_{a}(t)$.

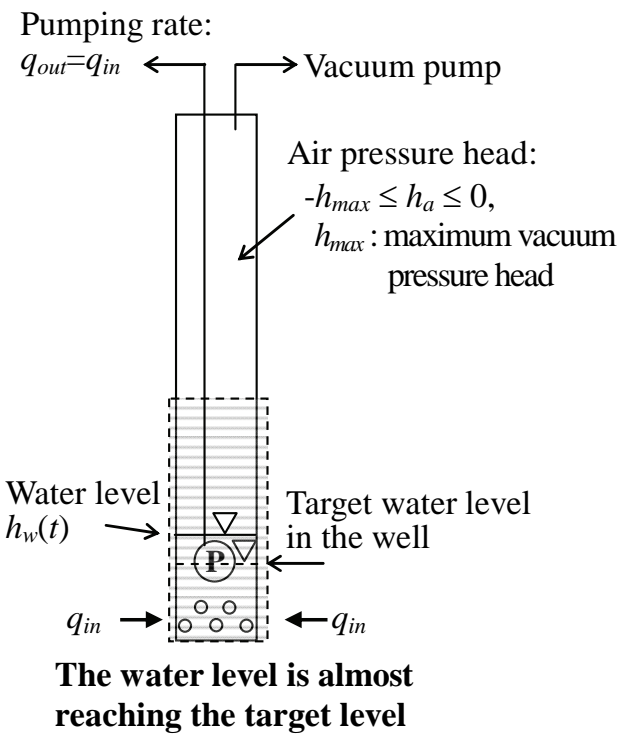

groundwater level. If $P_{a}(t)$ is set close to atmospheric pressure $P_{a}(t) \approx 0, H_{s}(t)$ will be equal to $h_{w}(t) . H_{s}(t)$ will decrease when $P_{a}(t)$ is set at the maximum vacuum capacity. It should be noted that $H_{s}(t)$ in the high- permeability zone will be approximated equal to the potential head in the well, if the potential loss due to the water flow through the well aperture and gravel zone is negligible. In the numerical simulation for the groundwater flow, the potential $H_{s}(t)$ or pressure head $h_{s}(t)$ shown in Eqn. (4) can be given as the boundary condition at the well screen. It should be noted that continuity equation Eqn. (5) is simultaneously integrated with Eqn. (1). The change in $h_{w}(t)$ is given to Eqn. (3) to update $h_{s}(t)$ and then $h_{s}(t)$ is used as the boundary condition for Eqn. (1). Eqns. (1) and (5) are coupled through $q_{i n}$ using Eqns. (6), (7), and (8). Water depth in the well $h_{w}(t)$ described by Eqn. (5) changes with $q_{\text {in }}$ and $q_{\text {out }}$. When $h_{s}(t)$ as boundary condition for the groundwater flow changes, $q_{\text {in }}$ is affected. Remember that the groundwater discharge from the NWP well $q_{\text {out }}$ is controllable up to its maximum pump capacity $Q_{\max }$. Therefore, there are two control variables for the NWP well: $P_{a}(t)$ and $q_{\text {out }}$. It is necessary to take account of the groundwater table around the well. If the groundwater table decreases too much, soil air above the groundwater table may be sucked into the pumping well. If this situation occurs, $P_{a}(t)$ will also weaken, resulting in a low pumping power. In conclusion, drawdown of groundwater by the NWP is controlled by the water balance in the well and the three-dimensional groundwater flow.

The left-hand side of Figure 4 illustrates the situation when the pump is ready to start. The pumping rate in the well, $q_{\text {out }}(t)$, will reach its maximum ca- pacity $Q_{\max }$, while $P_{a}(t)$ gradually decreases with time. The right-hand side of Fig. 4 illustrates the situation when water level in the well almost reaches the target elevation. At this stage, $q_{\text {out }}$ needs to be balanced by $q_{i n}$. Process control is used to optimize the water level. This is exemplified as follows:

1 ) The water pumping rate $q_{\text {out }}$ is set equal to $Q_{\max }$, as soon as the switch is on.

2) Since $q_{\text {in }}$ for the initial stage is less than $Q_{\max }$, drawdown of water level in the well will start to occur.

3) Monitor the water level in the well, and set the pumping rate $q_{\text {out }}$ equal to $q_{\text {in }}$ so that the water level in the well is maintained at steady state.

The air pressure $P_{a}(t)$ decreases from atmospheric pressure to the minimum negative pressure $(-7 \mathrm{~m}$ in the present simulation) after a few minutes and $P_{a}(t)$ is maintained at this level. The water level in the well gradually decreases. An instantaneous drawdown of water level in the well could cause instability in the numerical simulation. However, since the pump capacity is limited, a quick drawdown is not likely.

\section{(4) Apparent permeability and boundary condi- tion at the wire screen}

The aquifer permeability was set at $5.0 \times 10^{-5} \mathrm{~m} \mathrm{~s}^{-1}$. An apparent permeability for the wire screen region (thin space between the wire screen and exterior of the well wall of NWP) was set equal to $2.0 \times 10^{-2} \mathrm{~m} \mathrm{~s}^{-1}$. This is 400 times larger permeability compared to the aquifer soil. Note that for actual sites it is necessary to use the permeability based on field tests.

Figure 5 illustrates the calculation grid around the water intake aperture. The thick line is the well wall. 


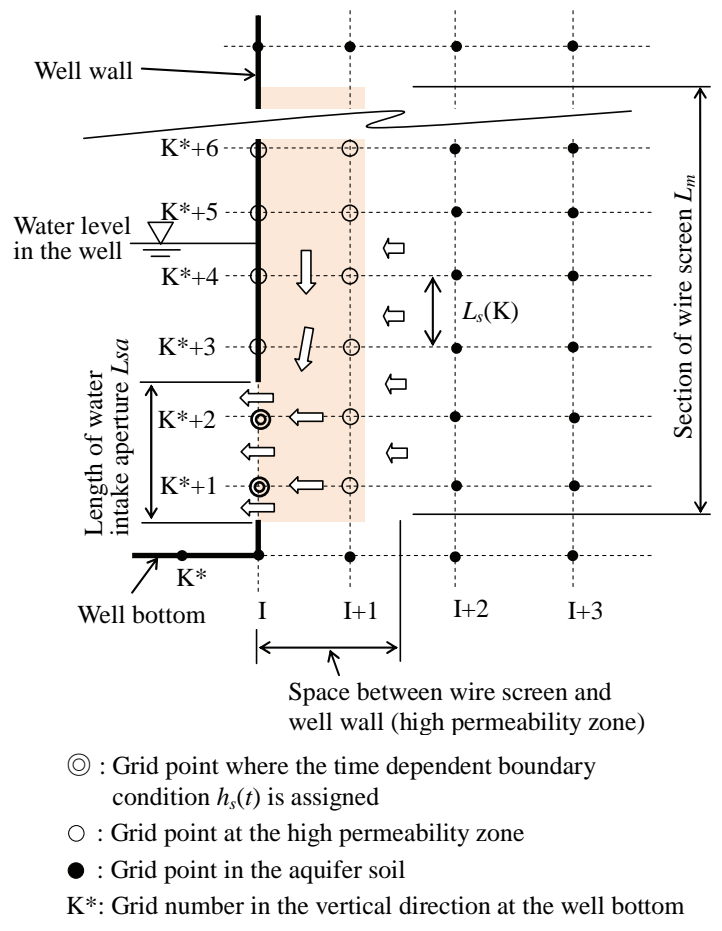

inflow, and air pressure in the well.Fig. 5 Grid meshes near the water intake anerture.

Impervious boundary condition is given at these grid points. The water intake aperture is represented by double circles and grid points by $\mathrm{K}=\mathrm{K}^{*+1}$ and $\mathrm{K}^{*+2}$ in the vertical direction, in which $\mathrm{K}^{*}$ denotes the grid number of the well bottom in the vertical direction. Also, $\mathrm{K}=\mathrm{K}^{*+3}, \cdots$, and $\mathrm{K}^{*+6}$ denote the grid number of the section of wire screen in the present simulation. The colored region represents the high-permeability zone at the space between the exterior well wall and wire screen. For permeability in the numerical simulation, the harmonic average of the adjacent grids is used.

\section{NUMERICAL METHOD}

In the following example, the groundwater inflow through the aperture, $q_{i n}$, is obtained by summation according to Eqn. (8). The water pressure head $h_{s}(t)$ shown in Eqn. (3) or the piezometric head $H_{s}(t)$ in Eqn. (4) is given at grid points for intake aperture at every time step. The permeability of the original aquifer soil is equal to the saturated permeability as long as the negative pressure region is maintained outside the well. Whether the soil near the well is saturated or unsaturated by the groundwater can be evaluated by checking the curved interface with zero water pressure head $h(x, y, z, t)$ during simulation. In practice, the location of zero pressure is the point where $h(x, y, z, t)$ changes from positive to negative values. In the NWP method, a negative water pressure head $h_{s}(t)$ is given as boundary condition at the aperture of water intake where soil is saturated. This assumes that the groundwater table remains at a high level. Therefore, the permeability near the NWP well is equal to the saturated permeability $k_{s}$ even though the water pressure head is negative. Needless to mention, the other parameters, $\eta$ takes 1 and $C_{w}$ takes 0 in Eqn. (1), respectively. In the vadose zone above the groundwater table, the water pressure head $h$ is negative. On the other hand, the water pressure head below the groundwater table is positive. As mentioned earlier, the water pressure head near the NWP well becomes negative when vacuum is applied. This means that there should be another interface where the water pressure head will be zero. Typically, such a location is found between the saturated domain with $h>0$ and $h<0$ around the well. During simulation, a curved interface with $h=0$ develops.

In summary, there are two regions with negative water pressure head: The first is in the unsaturated zone. In this region, the permeability changes with volumetric water content. The second is the region where negative water pressure propagates. Here, the permeability is equal to $k_{s}$ because soil is saturated. The detailed calculation algorithm to identify the unsaturated region with negative pressure head is presented in Figure 6. The groundwater table elevation is found from the numerical solution as the location with the zero pressure head changes from positive to negative values. Similarly, there are grid points with negative pressure head in the saturated region around the well screen. The location of the groundwater table and the curved interface, which is formed around the well screen, is easily plotted using commercial software for contour mapping. It should be noted, however, that judgment is necessary for the permeability coefficient when water is saturated, but the calculated pressure head is negative. Such condition can be found as condition (II) in Fig. 6. In the present study, the water level $h_{w}(t)$ in the NWP well was controlled so that the groundwater level was maintained higher than the curved interface that formed around the NWP well. It is important to note that the soil at any grid points can remain below the groundwater table when such a control is done.

The formation of the NWP region around the pumping well is confirmed by several reports from axisymmetrical laboratory experiments and numerical simulations ${ }^{4), 5)}$. However, the behavior of the three-dimensional NWP flow for various conditions has not yet been sufficiently investigated for practical applications at construction sites. In the present study, the finite difference method with successive over-relaxation (SOR) was adopted. Needless to mention, the finite element method is also applicable.In the present section, the two cases are simulated. 


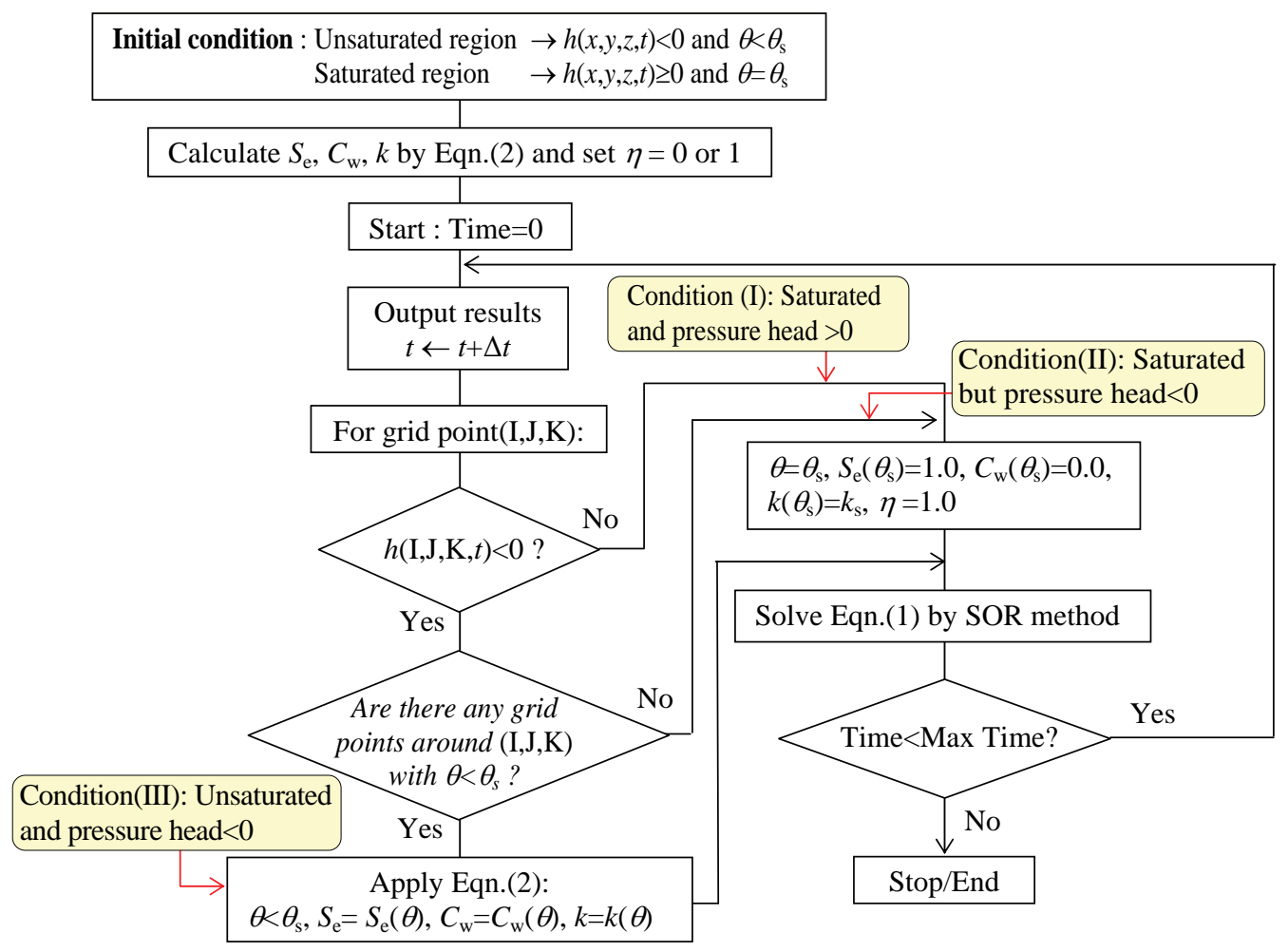

Fig. 6 Calculation flowchart to define the saturated region with negative pressure head.

The first case analyzes DW for unconfined groundwater with infinite radius of influence and uniform permeability. The groundwater enters from the well screen by gravity. Capillary water flow takes place along the groundwater table toward the well. Seepage boundary condition is adopted above the water level in the DW well. The elevation of the groundwater table in the unconfined aquifer is obtained by the numerical solution as mentioned previously.

At the vertical strainer above the seepage point in the DW well, the velocity component perpendicular to the well screen is set equal to zero as a boundary condition. The simulation is continued until the groundwater flow asymptotically reaches a steady state. The groundwater pumping discharge at steady state is compared with the well discharge formula. The second case is the numerical simulation of drawdown by the NWP method. The resulting groundwater drawdown, development of negative pressure zone, and change in pumping rate are compared with DW.

\section{(1) Calculation conditions}

\section{a) Geological and boundary conditions}

Figure 7 shows the boundary and hydro-geological conditions. Fig. 7(a) represents the plane view of the simulation domain. Fig. 7(b) is the calculation condition for the DW setup, and Fig. 7(c) for the NWP setup, respectively. The ground elevation is EL. +2.0 $\mathrm{m}$. The aquifer is homogeneous and isotropic. Two aquifer conditions were studied: Fig. 7(b) shows an impervious hydraulic base located at depth EL.-15 m (Case 1 and Case 2). The other one in Fig. 7(b) assumes that the impervious hydraulic base is located at EL.-25 m (Case 3). Rainwater infiltration is not considered. The boundary condition is set on the square $100 \mathrm{~m}$ apart from the center of the calculation domain. The groundwater level is set at EL. $+1.0 \mathrm{~m}$ as a constant boundary condition. Note that the square domain is approximated by a cylinder with equivalent areal size when the well formula is applied. In the present case, a radius of $112.8 \mathrm{~m}$ gives the equivalent areal size. Similarly, the equivalent well radius with $0.258 \mathrm{~m}$ is used to represent the $0.5 \mathrm{~m} \times 0.5 \mathrm{~m}$ square mesh. The bottom of the well is set at the impervious hydraulic base (EL. $-15 \mathrm{~m}$ ). The water level in the well is maintained at $4 \mathrm{~m}$ above the hydraulic base, corresponding to EL. $-11 \mathrm{~m}$. The bottom of the well is the same in Case 1 and Case 2, but the water level is maintained at EL. $-4 \mathrm{~m}$. For Case 3, the bottom of the well is set at a depth of the hydraulic base (EL.-25 $\mathrm{m})$, and the water level in the well is set at EL.-20 m. Fig. 7(c) illustrates the NWP well. As shown, the bottom of the well is set at EL.-14 m and the hydraulic base at EL.-15 m. The water intake aperture is set at EL.-14 m. The length of the intake aperture is $0.5 \mathrm{~m}$. 


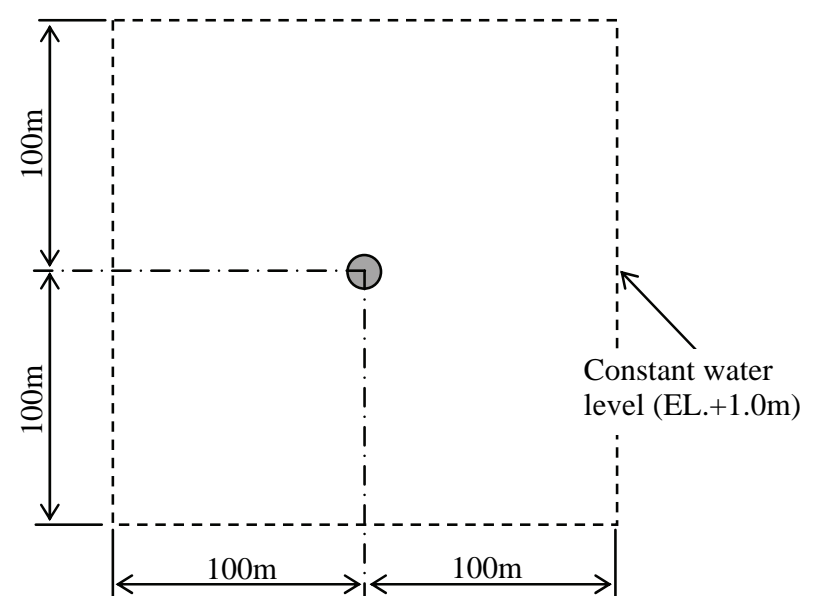

(a) Plane view of the calculation region

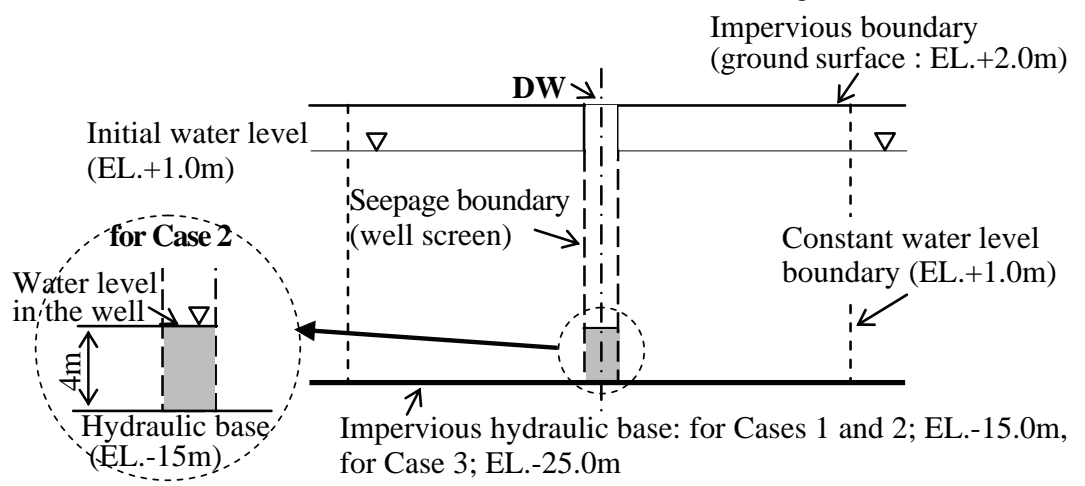

(b) Calculation condition for DW

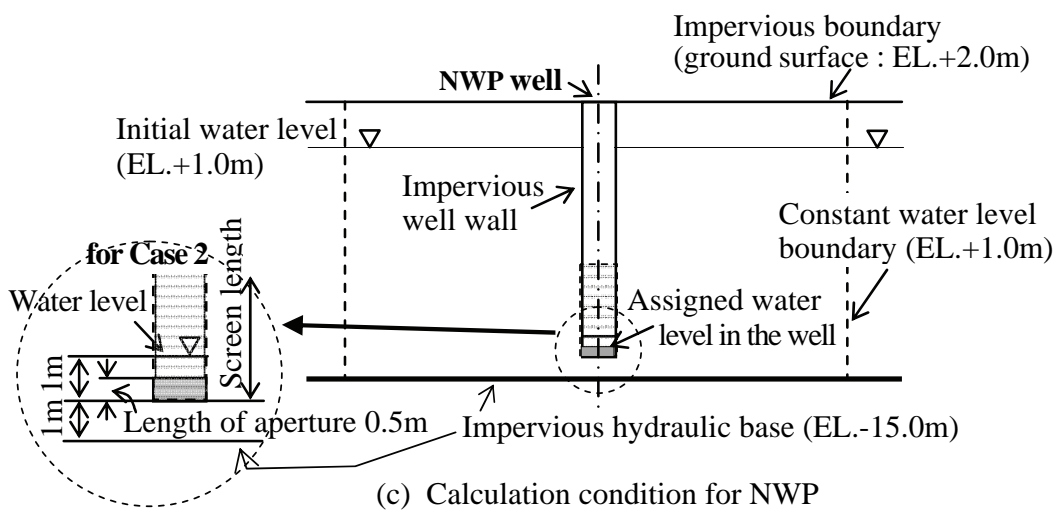

Fig. 7 Boundary and hydro-geological conditions.

The wire screen is $6 \mathrm{~m}$ long from the well bottom. The target water level in the NWP well is set $1 \mathrm{~m}$ above the bottom. Table 2 summarizes the simulation condition.

\section{b) Grid size and time increment}

Figure 8 shows a plane view of the finite difference grid used for the discretization of Eqn. (1). A fine grid in $x$ and $y$ directions is used around the well in the horizontal plane. The minimum grid size at the well is $0.25 \mathrm{~m}$, while a $26.2 \mathrm{~m}$ grid is used near the constant water level boundary. In the vertical direction, $0.2 \mathrm{~m}$ uniform grids are used for the case with the hydraulic base EL.-15.0 m. The total number of grids in this case was 409,446. In the case where the hydraulic base is set at EL.-25.0 m, a $0.25 \mathrm{~m}$ uniform grid size is used from the ground surface down to the level in the well $(-20 \mathrm{~m})$, and then the grid size is gradually increased toward the hydraulic base. The number of grids in this case became 433,251.

The initial groundwater elevation is set at EL. +1.0 $\mathrm{m}$. A static pressure distribution is initially assumed. In the NWP simulation, there is a possibility that a large gradient of the piezometric head may occur around the pumping well with time due to the effect of air pressure $P_{a}(t)$. To avoid unstable fluctuations in the numerical simulation for the initial period, the time increment $\Delta t$ was set to 0.01 seconds and then gradually increased at the rate of 1.01 every time step until $\Delta t$ reached 6.0 seconds. The convergence criteria 
Table 2 Calculation condition for DW and NWP.

\begin{tabular}{l|c|c|c|c}
\hline \multicolumn{1}{c|}{ Unit (m) } & DW(case1) & DW(case2) & DW(case3) & NWP \\
\hline $\begin{array}{l}\text { Elevation of ground } \\
\text { surface (EL) }\end{array}$ & +2.0 & +2.0 & +2.0 & +2.0 \\
\hline $\begin{array}{l}\text { Elevation of hy- } \\
\text { draulic base (EL) }\end{array}$ & -15.0 & -15.0 & -25.0 & -15.0 \\
\hline $\begin{array}{l}\text { Elevation of well } \\
\text { bottom (EL) }\end{array}$ & -15.0 & -15.0 & -25.0 & -14.0 \\
\hline $\begin{array}{l}\text { Target water level } \\
\text { (EL) }\end{array}$ & -4.0 & -11.0 & -20.0 & -13.0 \\
\hline $\begin{array}{l}\text { Groundwater level } \\
\text { at the calculation } \\
\text { boundary (EL) }\end{array}$ & +1.0 & +1.0 & +1.0 & +1.0 \\
\hline \begin{tabular}{l} 
Strainer length (EL) \\
\hline $\begin{array}{l}\text { Elevation of water } \\
\text { intake aperture }\end{array}$
\end{tabular} & $-15.0 \sim+1.0$ & $-15.0 \sim+1.0$ & $-15.0 \sim+1.0$ & $-14.0 \sim-8.0$ \\
\hline $\begin{array}{l}\text { Air pressure } \\
\text { head(m) }\end{array}$ & 0.0 & 0.0 & 0.0 & $-13.5 \sim-14.0$ \\
\hline $\begin{array}{l}\text { Calculation size of } \\
\text { square(m) }\end{array}$ & 200 & 200 & 200 & -7.0 \\
\hline
\end{tabular}

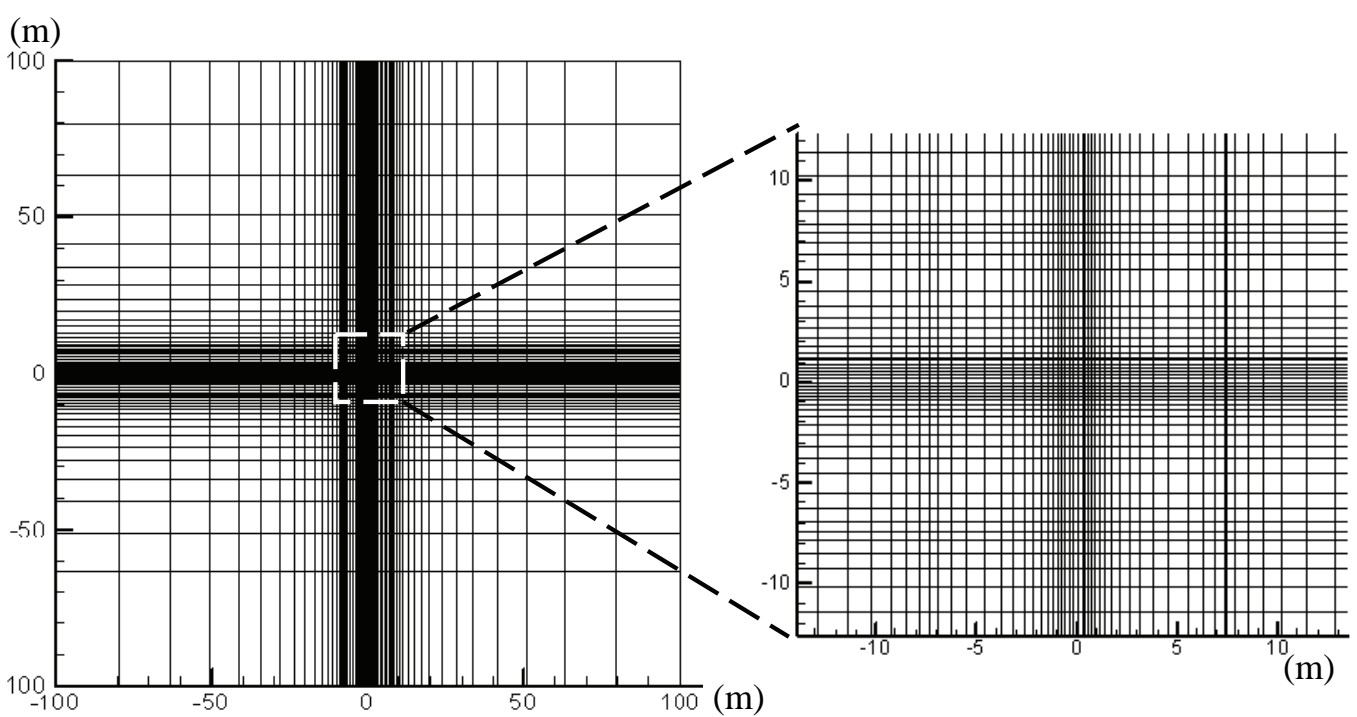

Fig. 8 Plane view of the finite difference mesh.

in the SOR for the finite difference method was set to satisfy $\left|5.0 \times 10^{-4}\right| \mathrm{m}$ at every grid point. This convergence criterion is considered to be sufficiently small.

\section{(2) Numerical simulation for DW and comparison with the well formula}

The accuracy of the numerical model was checked by numerical simulation for DW. After the accuracy of the numerical solution for DW was confirmed, the calculation conditions of NWP were given to the same program. Once the accuracy of the DW was confirmed, the NWP solution would be reliable. The two-step confirmation made sure that the numerical program for groundwater drawdown by DW was applicable for the NWP simulation by changing the boundary conditions.

Figure 9 illustrates the groundwater level obtained by the Dupuit's assumption ${ }^{10) 15)}$ for the unconfined flow neglecting unsaturated flow. It is assumed that the vertical velocity component far from the pumping well is negligible. It should be noted, however, that the formula for pumping rate is valid even when the vertical component is neglected. The formula for pumping rate $Q_{\text {well }}$ and the shape of groundwater level $H(r)$ are expressed by Eqns.(9a) and (9b): 


$$
\begin{gathered}
Q_{\text {well }}=\frac{\pi k\left(H_{R}^{2}-H_{w}^{2}\right)}{\ln \left(R / r_{w}\right)} \\
H(r)=\sqrt{H_{R}{ }^{2}-\frac{H_{R}{ }^{2}-H_{w}{ }^{2}}{\ln \left(R / r_{w}\right)} \cdot \ln (R / r)}
\end{gathered}
$$

where $H_{R}$ is the groundwater level at the radius of influence $R, H_{w}$ is the water level in the well, and $r_{w}$ is the well radius. There are many literatures discussing the accuracy of numerical codes. In general, the solutions are accurate if careful attention is paid to the discretization of the fundamental equations ${ }^{10)-15)}$. Because the present paper examines the effect of applying vacuum in a pumping well on the groundwater flow, simple boundary conditions are considered. The results for the three cases are presented in Fig. 9. In each case, the hydraulic base of the aquifer and the water level in the well are different in the numerical simulation. The full line for each case shows the groundwater level by the numerical solution and the broken line is obtained by the well formula in Eqn. (9b). D. Chenaf and R. Chapuis ${ }^{15)}$ performed a detailed analysis of groundwater level for an unconfined aquifer and seepage face at a well strainer. They remarked that the groundwater level in the Dupuit's formula (9b) coincides with the observed groundwater level in the distant region beyond $1.5 \times H_{R}$. However, the deviation between the well formula and the numerical solution of the groundwater level becomes large in the region within $1.5 \times H_{R}$. This fact is also seen in Fig. 9 and Fig. 10. In Fig.10, the three lines represent the piezometric head at EL.-12, EL.-16, and EL.-21.7 m. The groundwater level is also plotted in the same diagram. The present numerical solution confirms that the Dupuit's assumption for the groundwater level is not valid for the region within $1.5 \times H_{R}$.

Strictly speaking, the groundwater discharge to the well is different from the well formula. The reason for this is the disregard for the unsaturated water flow above the groundwater table. This was also noted by D. Chenaf and R. Chapuis ${ }^{15)}$. They concluded that the groundwater discharge by the numerical simulation is at most 5\% larger than that of the well formula. Since the numerical simulation in the present study is carried out for the saturated-unsaturated flow, this difference is reasonable. The steady state pumping rate by the present numerical simulation is listed in Table 3. The difference coincides with their remarks. It is clear that the Dupuit's formula for the pumping rate is analytically derived based on the continuity of water during steady state. Although neglecting the vertical velocity component is not valid near the

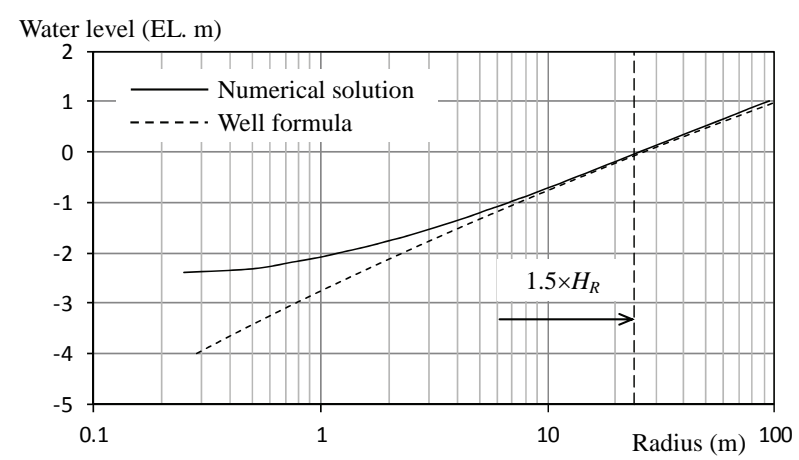

(a) Case1 (Hydraulic base at EL.-15 m, water level in the well EL.-4 m)

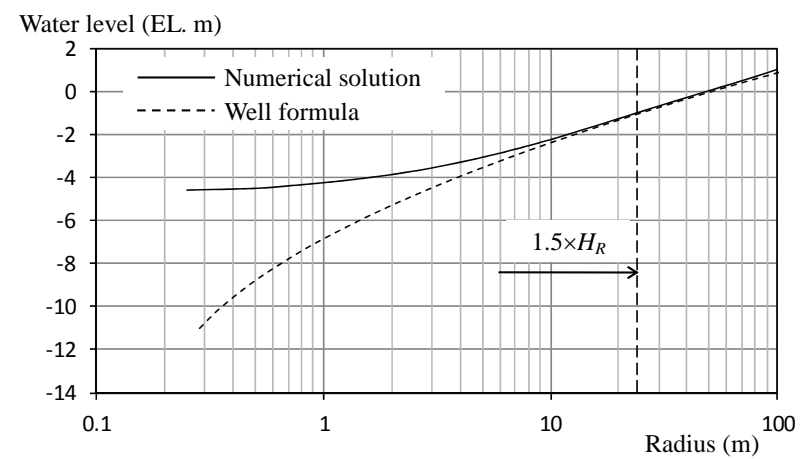

(b) Case 2 (Hydraulic base at EL.-15m, water level in the well EL.-11 m)

Water level (EL. m)

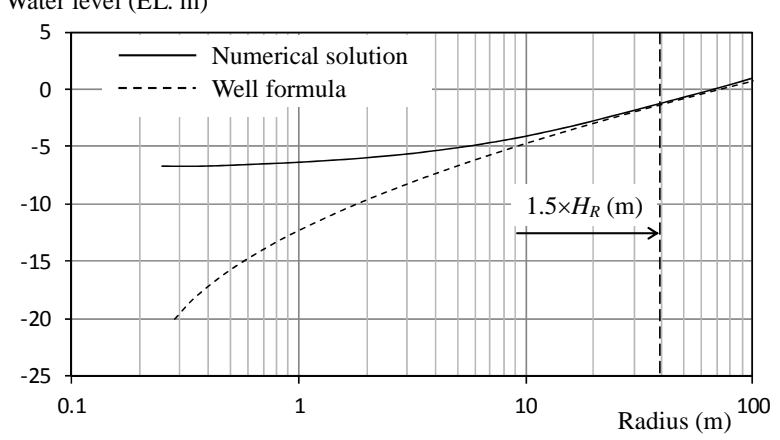

(c) Case 3 (Hydraulic base at EL.-25 m, water level in the well EL.-20 m)

Fig. 9 Groundwater table by numerical simulation and well formula in steady state.

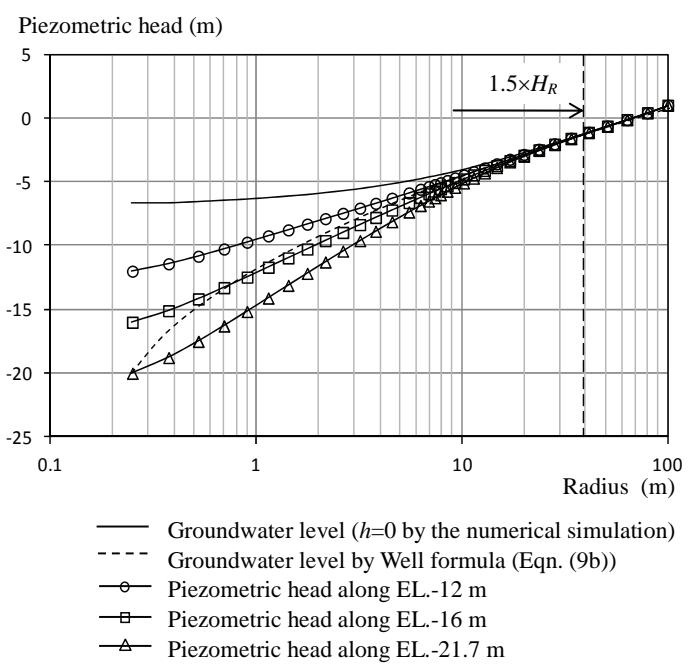

Fig. 10 Distribution of groundwater level and piezometric head by the numerical simulation and well formula (Case 3). 
Table 3 Comparison of groundwater discharge for Dupuit's formula Eqn.(9a) and numerical simulation for DW.

\begin{tabular}{c|c|c|c}
\hline Cases & $\begin{array}{c}\text { (D) Dupuit's } \\
\text { formula }\end{array}$ & $\begin{array}{c}\text { (N) Numerical } \\
\text { solution for DW }\end{array}$ & $\begin{array}{c}\text { Deviation } \\
\text { (D)-(N) }\end{array}$ \\
\hline Case 1 & 0.215 & 0.224 & $-3.7(\%)$ \\
Case 2 & 0.378 & 0.389 & $-3.1(\%)$ \\
Case 3 & 1.024 & 1.057 & $-3.1(\%)$ \\
\hline
\end{tabular}

pumping well, the continuity of water is kept at any horizontal coordinate when the groundwater flow along the capillary fringe is neglected.

It should also be noted that the numerical results for steady state pumping rate by Chenaf and Chapuis $^{15)}$ with FEM and by the authors with FDM are very close. The height of the groundwater table and the pumping rate at steady state are indispensible factors to be checked with numerical solutions. Since the NWP program gives the reliable result for these factors at steady state after the transient period, it is expected that the present program also shows reasonable behaviors during the transient period.

\section{(3) Characteristics of groundwater table near the NWP well}

Figure 11 shows the elevation of the groundwater table, piezometric head distribution, and the negative pressure-saturated region inside a radius of $10 \mathrm{~m}$ after 4 days, obtained by the numerical simulation for DW and NWP. Fig. 11(a) represents the groundwater table of DW for Case 2 in Fig. 7(b), while Fig. 11(b) is a result of NWP. In the case of DW, the gradient of groundwater table is steeper than that of the NWP near the well strainer. The reason for NWP having a more flat gradient of the groundwater table near the well screen can be explained as follows: In the case of NWP, the water intake aperture is suited at the lowest part of the well and impermeable boundary condition is set at the rest of the well wall. This condition for the NWP results in a groundwater table that becomes flat near the well wall.

On the other hand, the well strainer is set along the entire depth in the case of DW. This structure allows the groundwater to flow into the well through the strainer at any depth. The difference in the groundwater table near the DW and NWP wells is a result by the given different boundary conditions.

\section{NUMERICAL ANALYSIS FOR A HY- POTHETICAL EXCAVATION}

As mentioned previously, the NWP simulation can be done by changing the boundary conditions of any software developed for DW. The water balance equation for the well is recommended to control air pressure. In this section, the characteristics of ground

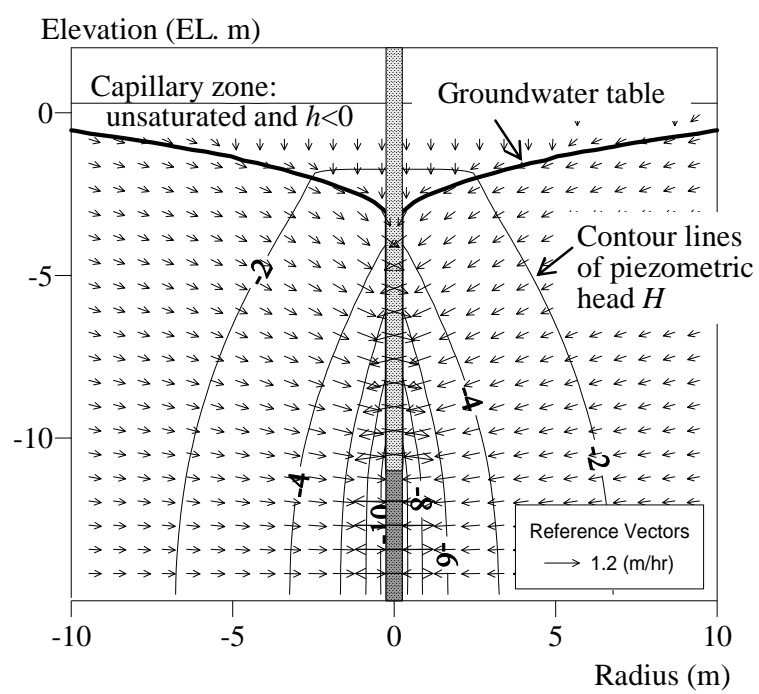

(a) Groundwater table and piezometric head around the well by DW after 4 days.

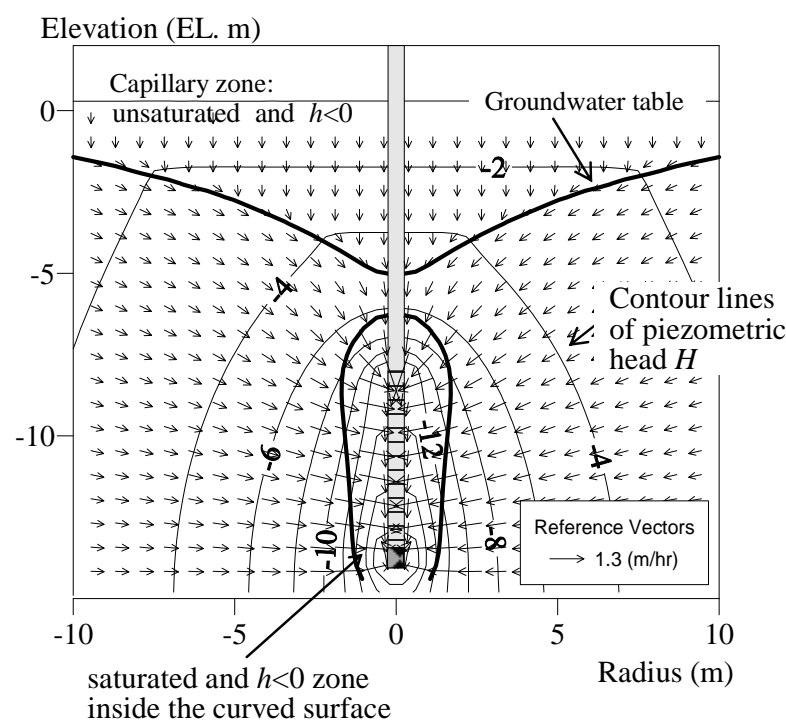

(b) Groundwater table and piezometric head around the well by NWP after 4 days.

Fig. 11 Groundwater table and piezometric head distribution around the well after 4 days by DW and NWP.

water flow and drawdown of the piezometric head by NWP are presented.

\section{(1) Calculation condition}

Let us examine the case where the well bottom is lower than the sheet wall. Figure 12 shows a plane view of the hypothetical calculation domain having $200 \mathrm{~m}$ sides in $x$ and $y$ directions. Groundwater is supplied from these sides. The square zone is the excavation site with $14.8 \mathrm{~m}$ length at each side. The excavation depth is enclosed by the sheet wall with depth reaching EL. $-21.7 \mathrm{~m}$, which is $3.3 \mathrm{~m}$ above the hydraulic base (EL. $-25 \mathrm{~m}$ ). Here, the permeability of the sheet wall is set equal to $1 \times 10^{-7} \mathrm{~m} \mathrm{~s}^{-1}$. The excavation depth is set at EL. $-10 \mathrm{~m}$, which is $12 \mathrm{~m}$ below the ground surface. Table 4 lists the well structure 


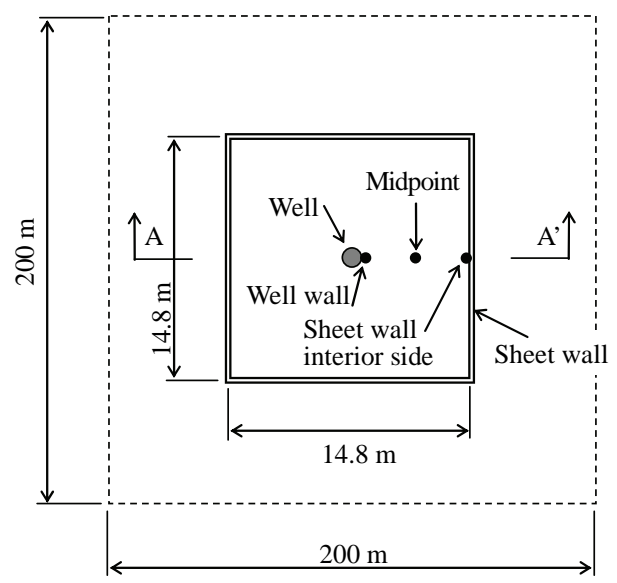

(a) Plane view of the calculation region

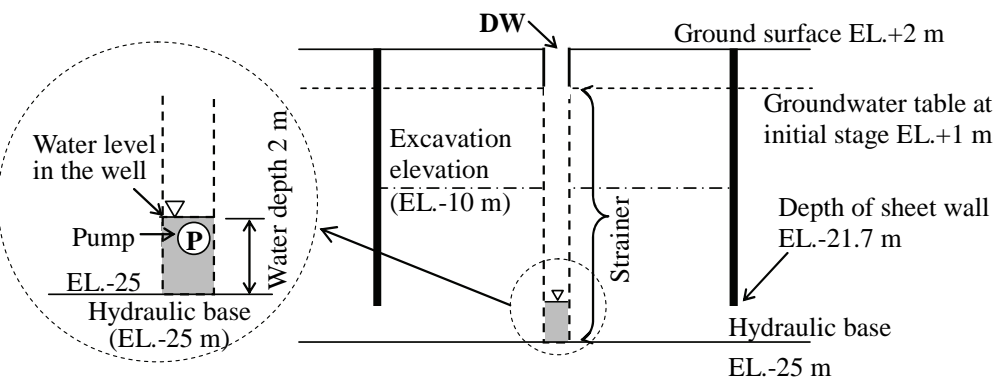

(b) Calculation condition for DW

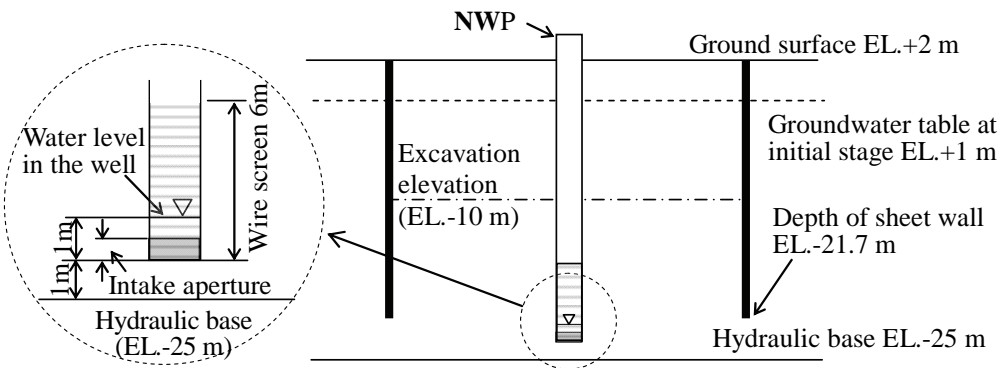

(c) Calculation condition for NWP

Fig. 12 Calculation domain and setup of DW, NWP, and sheet wall.

Table 4 Well and sheet wall characteristics of the excavation.

\begin{tabular}{l|c|c}
\hline & DW & NWP \\
\hline Well diameter & $500 \mathrm{~mm}$ & $500 \mathrm{~mm}$ \\
\hline Pumping capacity & $2.4 \mathrm{~m}^{3} \mathrm{~min}^{-1}$ & EL.-24 m $\mathrm{min}^{-1}$ \\
\hline Elevation of well bottom & EL.-25 m & EL.-23 m \\
\hline Strainer setting & $\leq$ EL. $+1.0 \mathrm{~m}$ & EL.-23.5 -24 m $\left(L_{s a}=0.5 \mathrm{~m}\right)$ \\
\hline Target water elevation for excavation & EL.-23 m & EL.-18 -24 m $\left(L_{m}=6.0 \mathrm{~m}\right)$ \\
\hline Position of wire screen & - & $\operatorname{EL}-21.7 \mathrm{~m}$ \\
\hline Bottom of sheet wall & EL.-21.7 m $\left(P_{a} / \rho_{w} g\right)=-7 \mathrm{~m}$ \\
\hline Minimum vacuum head & - & \\
\hline
\end{tabular}




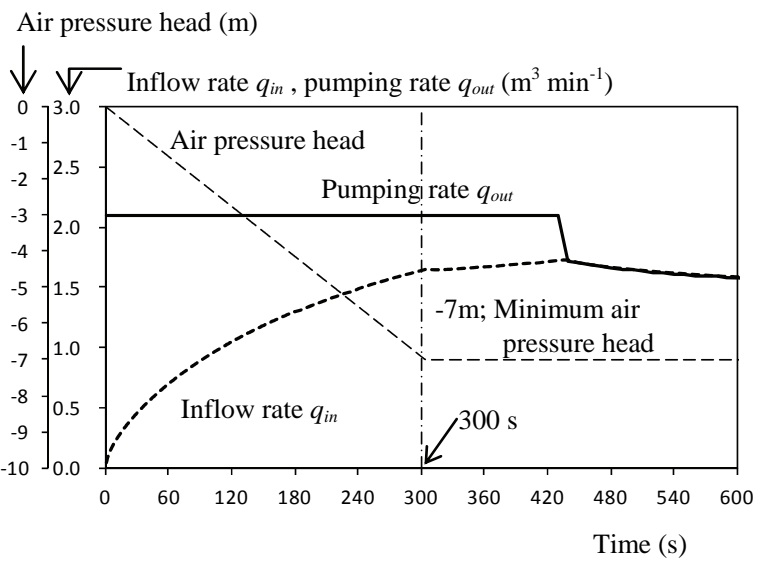

Fig. 13 Variations of pumping rate, groundwater

and pump capacity. The water intake aperture for NWP is set at EL. $-23.5 \sim-24.0 \mathrm{~m}$ with $L_{s a}=0.5 \mathrm{~m}$. The wire screen length is set between EL. -18 and $-24 \mathrm{~m}$ with $L_{m}=6.0 \mathrm{~m}$.

\section{(2) Results}

a) Variations in groundwater inflow, pumping discharge, and air pressure in the NWP well

In the present example, the maximum water pump capacity was set to $2.1 \mathrm{~m}^{3} \mathrm{~min}^{-1}$ and the negative maximum capacity of vacuum pressure head in the well was $-7 \mathrm{~m}$. Figure 13 shows the variations in groundwater inflow rate into the well, pumping rate, and air pressure head immediately after the water and air pumps are switched on. The air pump is operated so that the air pressure decreases linearly down to -7 $\mathrm{m}$ taking 300 seconds, and then maintained at $-7 \mathrm{~m}$ as air pressure head. In the figure, the water inflow rate slightly changes after 300 seconds when the air pressure head is fixed at $-7 \mathrm{~m}$.

Figure 14 shows the variations in pumping rate and water level in the well. With a constant pumping rate at $2.1 \mathrm{~m}^{3} \mathrm{~min}^{-1}$, the water level in the well decreases as calculated by the water balance in Eqn. (5). After 440 seconds, the water level reaches the target water level EL. $-23 \mathrm{~m}$. The groundwater inflow rate increases up to $1.7 \mathrm{~m}^{3} \mathrm{~min}^{-1}$ after 440 seconds. It should be noted that the water level in and around the well further decreases and it may reach the water intake aperture. Thus, there is a possibility that air in the unsaturated zone above the groundwater table may be sucked into the well. Once air enters the well, the vacuum effect will decrease. Therefore, water level, water pumping rate, and air pressure need to be controlled to avoid such a situation. In the present example, the following hypothetical operation was tested. Figure 15 shows the changes in water inflow rate $q_{\text {in }}$ through the aperture, water pumping rate

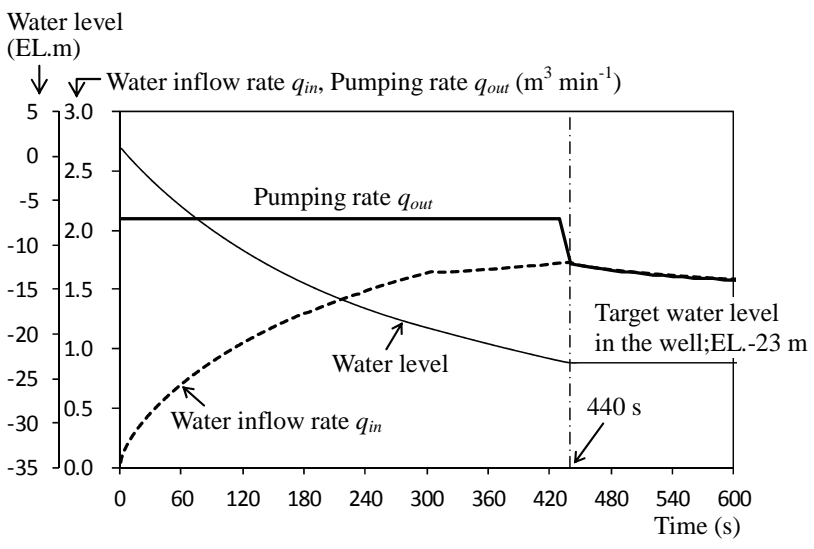

Fig. 14 Variations of pumping rate, water inflow rate, and water level in the well.

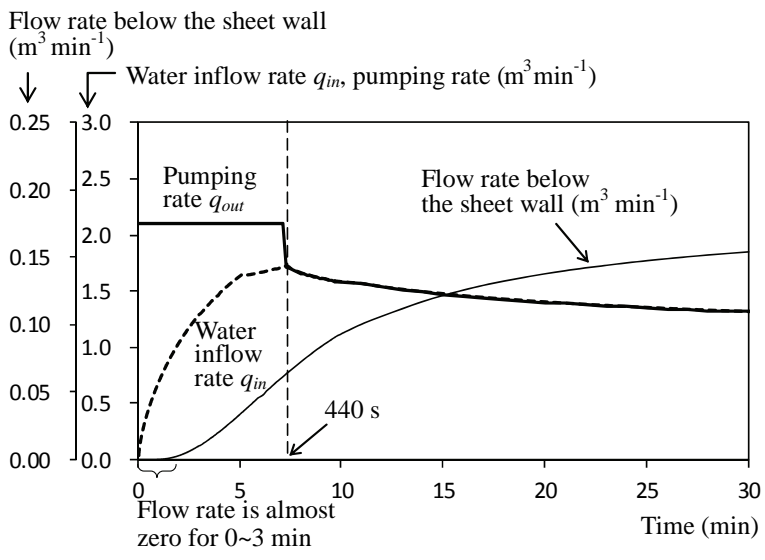

Fig. 15 Variations of pumping rate, water inflow rate, and flow rate below the sheet wall.

$q_{\text {out }}$, and flow rate under the sheet wall. In the hypothetical operation, $q_{\text {out }}$ is adjusted equal to $q_{\text {in }}$ so that the water level in the well can be maintained at EL. $-23 \mathrm{~m}$ after 440 seconds.

\section{b) Characteristics of groundwater drawdown time series}

The three thick lines in Figure 16 represent the variations in the groundwater drawdown at three locations immediately after start of pumping by NWP. The thickest line represents the variation at the exterior wall of NWP followed by the variation at the midpoint and the interior points of the sheet wall in Fig. 12. The broken lines show those of DW obtained at the same points. The variations at the three points by NWP are seen to be almost identical until 16 hours. Distinct delays are observed after 23 hours. First, the drawdown at the interior point of the sheet wall is delayed. The drawdown at the midpoint follows.As time passes, the deviation becomes large. In the case of DW, more distinct changes can be observed. The largest drawdown occurs at the well wall. 

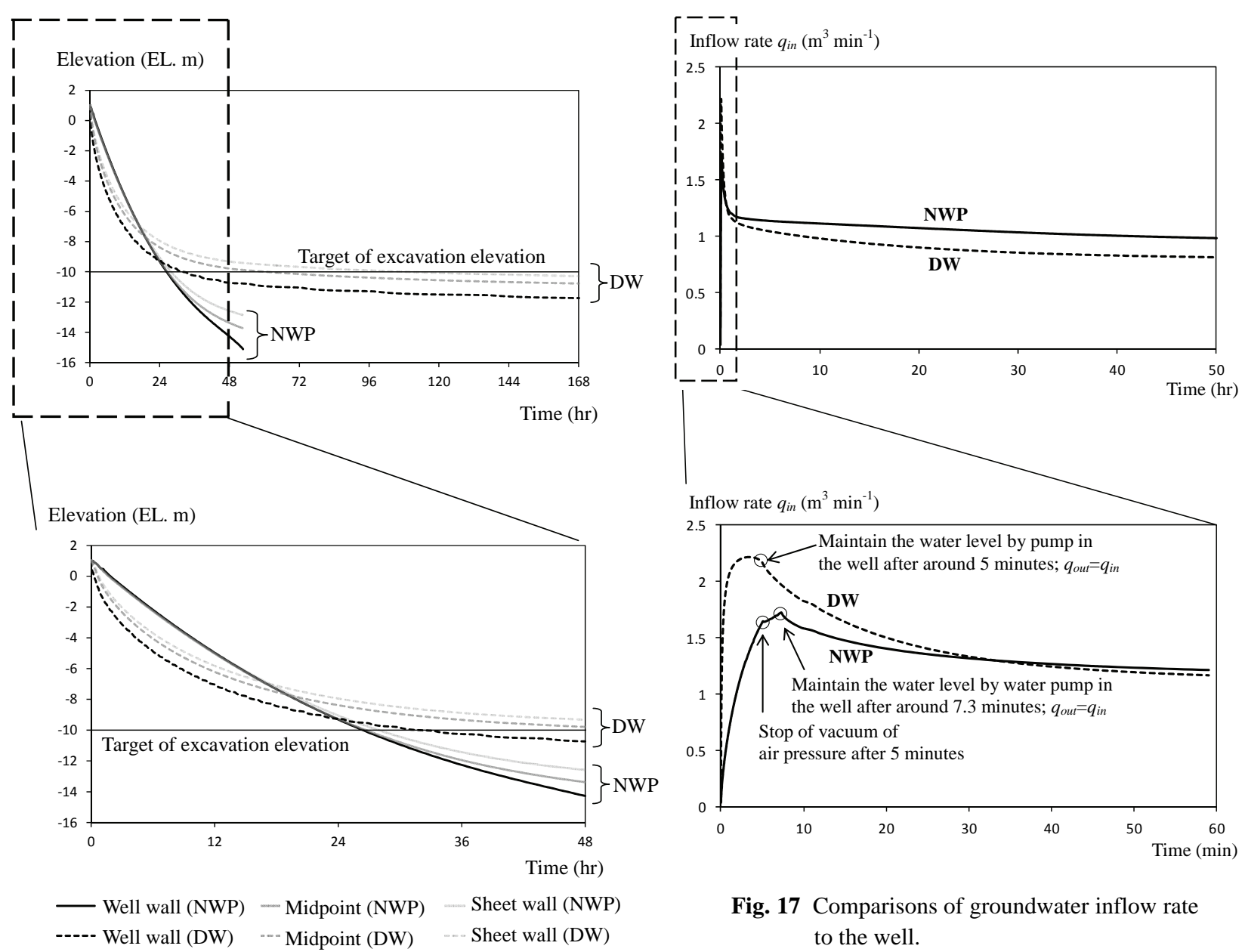

Fig. 17 Comparisons of groundwater inflow rate to the well.

Fig. 16 Comparison of groundwater drawdown between NWP and DW.

The drawdown at the midpoint and interior points follow. The deviations gradually increase but they approach a steady state. Only 17 hours after the start, the drawdown of the groundwater level at the three points by DW is larger than that by NWP. This can be explained by the fact that the water inflow rate depends on the product of velocity and inflow area. The DW has a longer strainer than NWP as long as the groundwater level remains high. This means that more groundwater can enter the DW well than that of the NWP. On the other hand in NWP, the inflow takes place through the aperture with a screen length $L_{m}=6.0 \mathrm{~m}$, which is shorter than that for the DW. Besides, as shown in Table 3, the maximum capacity of DW is set to $2.4 \mathrm{~m}^{3} \mathrm{~min}^{-1}$ and this is larger than 2.1 $\mathrm{m}^{3} \mathrm{~min}^{-1}$ for the NWP. This implies that the inflow rate by DW for the initial period is large and water level therefore decreases quickly. The groundwater flow rate toward the excavation site below the sheet wall is almost 0 until $2 \sim 3$ minutes after pumping. After that, the groundwater flow rate under the sheet wall gradually increases during approximately 1 hour. After 1 hour, it reaches a constant rate. The groundwater pumping rate $q_{\text {out }}$ and the groundwater flow below the sheet wall become 1.060 and 0.185 $\mathrm{m}^{3} \mathrm{~min}^{-1}$, respectively, after 24 hours, and 0.990 and $0.195 \mathrm{~m}^{3} \mathrm{~min}^{-1}$, respectively, after 48 hours. It is confirmed that $q_{\text {out }}$ asymptotically approached the groundwater flow below the sheet wall. Figure 17 shows the change in the groundwater inflow rate for the NWP and DW. The inflow rate to DW well increases sharply during the first minute and then gradually increases up to 5 minutes.

The water level in the well approaches the target level after 5 minutes. Therefore, the pumping rate $q_{\text {out }}$ is set equal to $q_{\text {in }}$ to maintain the same level. It should be noted in such operation that the water level in DW can be further lowered if the pumping rate $q_{\text {out }}$ is still larger than $q_{\text {in }}$.

However, in this case, unnecessary groundwater may be pumped up. In the case of NWP, the inflow rate in the well slowly increases up to 7.3 minutes and then decreases. This period, when the rising speed is changed, corresponds to the pump operation. After 5 minutes, the air vacuum pump is stopped. 


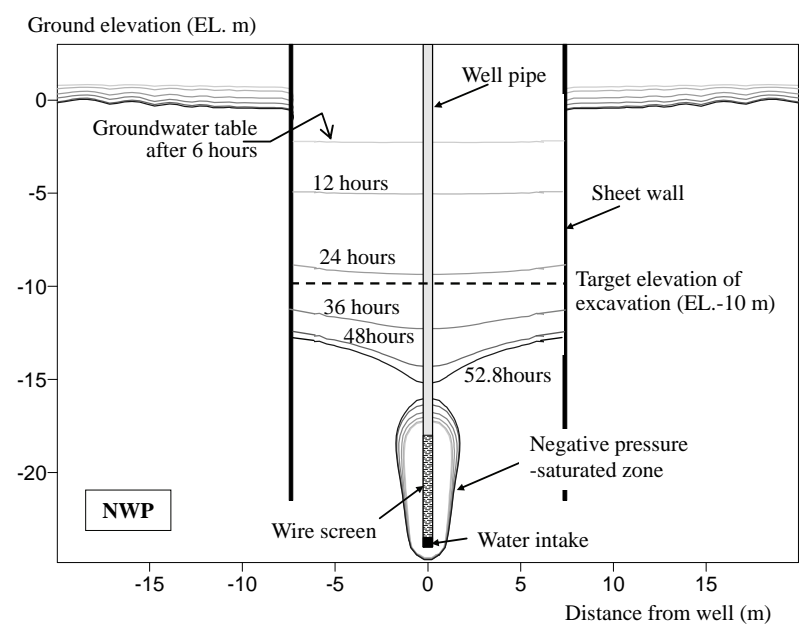

(a) Formation of negative water pressure around the well with time and drawdown of the water level inside the excavation site

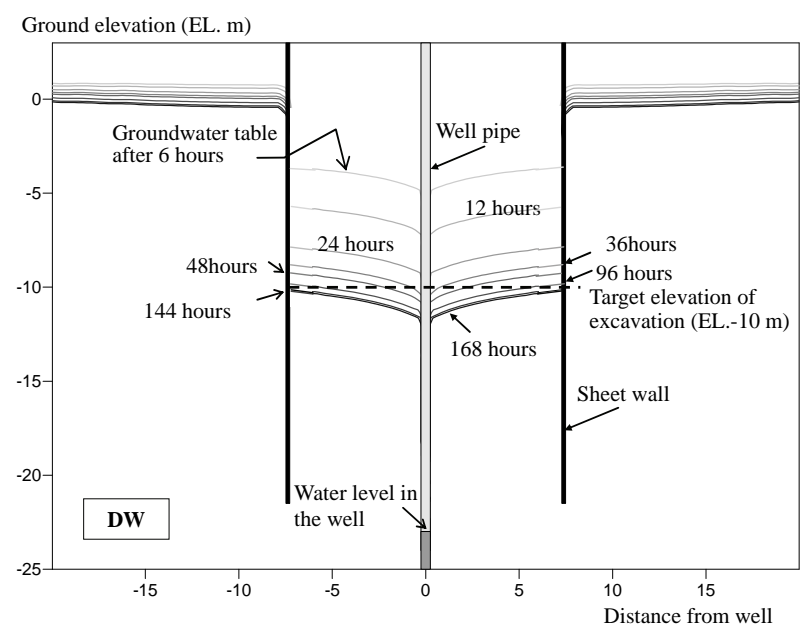

(b) Drawdown of the water level inside the excavation site

Fig. 18 Drawdown of groundwater table by NWP and DW.



Fig. 19 Changes in groundwater elevation $(\bullet)$ and highest point along the NWP well (०) with time.

On the other hand, at 7.3 minutes, the groundwater pumping rate is set equal to the inflow rate so that the water level in the well can be kept at the target level after 7.3 minutes. It should be noted that NWP has two control variables: the water pump discharge and the control of air pressure in the well. This advantage can be implemented by the water balance equation in which the air vacuum pressure in the well can be easily controlled.

\section{c) Characteristics of water level drawdown in the excavation site}

Figure 18 shows the groundwater table and the negative pressure-saturated zone along the A-A' cross section in Fig. 12(a). Fig. 18(a) represents the changes in the groundwater table and the negative pressure-saturated zone around the wire screen formed by NWP. Fig. 18(b) shows the change in groundwater table by DW.
The drawdown of groundwater table by NWP at the excavation site takes place uniformly during 12 24 hours. A negative pressure-saturated zone is formed around the well wall. This zone expands upwards along the wire screen. On the other hand for DW, the drawdown of the groundwater table during the first 6 hours is rapid but gradually decreases similar to that for the NWP. Specifically, the groundwater table seems to reach a steady state after 24 hours. The groundwater table shape by NWP at 24 hours is more horizontal, compared to the DW. It is also observed that the NWP drawdown of the groundwater table takes about 25 hours, while for DW it takes 96 hours until the groundwater table reaches the target level of excavation. To evaluate the groundwater table and the expansion of the negative pressure-saturated zone with time by NWP, schematic illustrations are shown in Figure 19. 


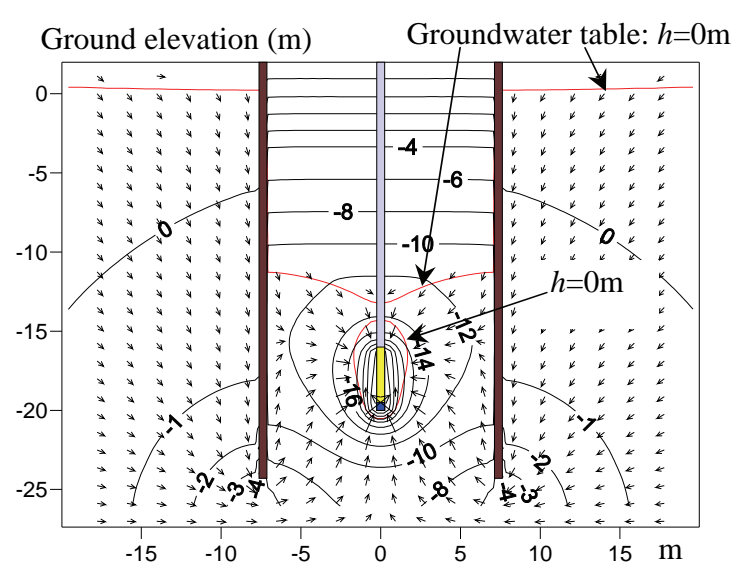

(a) Groundwater drawdown and piezometric head distribution by NWP with same strainer length (after 2 days)

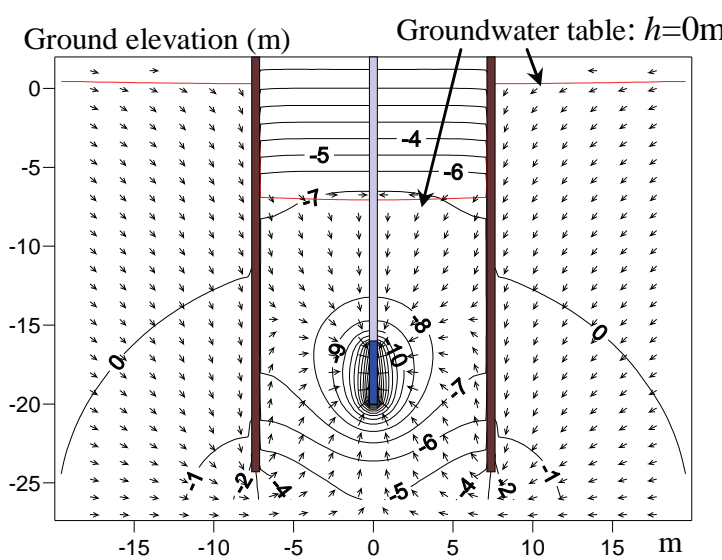

(b) Groundwater drawdown and piezometric head distribution by DW with same screen length (after 6 davs)

Fig. 20 Comparisons of groundwater table drawdown using NWP and DW, respectively.

The elevation of the groundwater table along the well wall and the line of zero water pressure head are presented. The symbol ' $\circ$ ' represents the highest point of the line of zero water pressure head, while ' $\bullet$ ' represents the lowest elevation of the groundwater table around the well wall at the left part of Fig. 19. It is observed that the groundwater table goes down and the negative pressure-saturated zone gradually expands with time. The two lines approach each other more closely after 48 hours. As explained previously, the groundwater table along the wire screen and the curved surface of zero water pressure head will meet unless either the water pumping rate is reduced or air vacuum pressure is weakened. Soil air in the unsaturated zone overlying the groundwater table will be quickly sucked into the well. As a result, the air vacuum in the NWP will be weakened. Then, the efficiency of the NWP decreases. To avoid such situations, the operator of NWP usually opens the valve to let air into the well.

\section{(3) Effect of well depth, length of strainer of DW, and wire screen of NWP}

It is important to analyze whether there are significant differences when the well depths, lengths of strainer of DW or wire screen of NWP are changed. The sheet wall is set deeper than that of the well depth. As shown in Figure 20, the target excavation depth is set at EL. -10 m for (a) NWP and (b) DW. In case (a), the water intake aperture is set at EL. $-20 \mathrm{~m}$ and the wire screen of length $4 \mathrm{~m}$ for the NWP. On the other hand, the strainer of $4 \mathrm{~m}$ is set for DW in case (b). The red thick lines with the notation ' $h=0$ ' in Fig. 20(a) after 2 days and Fig. 20(b) after 6 days represent the lines of zero water pressure head.

As explained previously, a curved interface with the notation ' $h=0$ ' is formed around the water intake

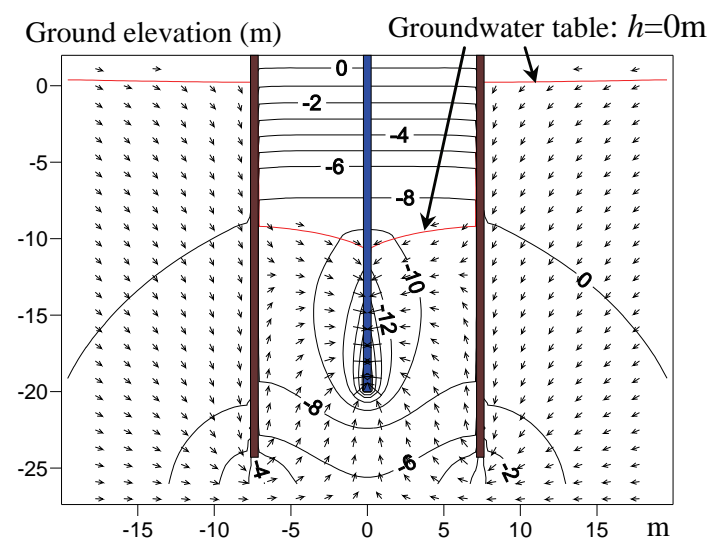

Fig. 21 Drawdown of groundwater table by DW when the screen is set along the well depth (after 6 days).

aperture in Fig. 20(a). This line indicates the boundary between the negative pressure-saturated zone as Condition (II) and positive pressure-saturated zone as Condition (I) in Fig. 6. The groundwater table inside the excavation site reaches the target depth EL. -10 m after 2 days. On the other hand, the groundwater table for case (b) is still above EL. $-7 \mathrm{~m}$ even after 6 days. This difference is caused by the larger gradient of the piezometric head toward the well for case (a) than the one for case (b). To analyze the effects of the strainer length for DW, a longer strainer is set over the entire depth as shown in Figure 21. It is seen that the groundwater table is lowered to EL. $-9 \mathrm{~m}$ after 6 days and the level is lower than in Fig. 20(b). However, the groundwater level is still higher than in Fig. 20(a). It is obvious in the present simulation that either the longer strainer or lower well elevation depth is necessary for DW if the groundwater needs to be lowered similar to that for NWP. 


\section{CONCLUSION}

The characteristics of the NWP method were analyzed and discussed. This method was used to enhance the drawdown of the groundwater table by simultaneous air vacuum and water pumping. The accuracy of the numerical model for the DW method was checked in advance of the NWP simulations. By comparing model results with research findings from literature and Dupuit's well formula, the numerical solution of DW for the groundwater table and the pumping rates at the steady state were shown to be in good agreement. Then, the NWP was applied to a hypothetical excavation site surrounded by a sheet wall. The following results were obtained:

1. The water balance equation for water in the pumping well was coupled with the groundwater flow simulation. The water balance, change in water level, effect of vacuum, water inflow and outflow in the well were considered. By this coupling, the time-dependent water pressure head in the well was set as the boundary condition for the groundwater flow simulation. It indicates that coupling of the water balance equation in the well with the numerical simulation for NWP is significant to control well operation.

2. The numerical simulation of DW was carried out to confirm the accuracy of the steady state pumping rate and the groundwater table. The numerical solution was compared with Dupuit's formula. The pumping rate by the numerical simulation of DW agreed reasonably well with Dupuit's formula. The elevation of the groundwater table was also in good agreement beyond the radius of $1.5 \times H_{R}$. The groundwater elevation inside the radius of $1.5 \times H_{R}$ deviated gradually toward the pumping well. These results are all similar as remarked by Chenaf and Chapuis ${ }^{15)}$.

3. In their paper, the groundwater pumping rate by the saturated-unsaturated numerical simulation for DW usually gave at most $5 \%$ larger value than that of Dupuit's formula. In the present simulation for DW, the deviation was $3 \sim 4 \%$ larger. This fact is also demonstrated by the present simulation.

4. In the numerical simulation for DW and NWP, the shape of groundwater table near the pumping well was steep for DW and flat for NWP. This difference was a result of the difference in the boundary condition assumed at the well wall. The drawdown speed of the groundwater table for the initial period by DW was faster than for NWP. However, its speed became slow and asymptotically reached a steady state. On the other hand, NWP could lower the groundwater table at an almost constant rate from the beginning.
5. The three virtual observation points were located at the well wall, midpoint, and interior of the sheet wall to compare the drawdown of the groundwater table. In the case of DW, the shape of drawdown was not the same. The drawdown speed of the groundwater table became slower with time. This implied that the groundwater table by DW was reaching a steady state. On the other hand, the drawdown rate of groundwater table was almost constant by the NWP. This is an advantage for excavation works.

6. The time necessary for drawdown by NWP was 2 days until the groundwater table was lowered to the target excavation elevation, while it took 6 days by DW when the same well strainer was used. Even with a $20 \mathrm{~m}$ strainer for DW, it took 6 days to lower the groundwater table below the target excavation elevation.

In the future, optimal control for groundwater drawdown can be automated if signals from pumping rate, air and water pressure gauges, and groundwater level near the NWP well are transmitted continuously.

The NWP has also been applied to remediation of soil and groundwater pollution by applying its strong vacuum power. Furthermore, it should be noted that air vacuum power can enhance water drainage, which results in compaction of the soil. Also, deformation of soil surface may take place if too much air vacuum power is applied. For these purposes, it is important to establish two-phase analyses for both water and gaseous phase transportation under the effect of the NWP.

ACKNOWLEDGMENT: The authors express their sincere appreciation to Mr. Sigekichi Takahashi, Asahi Co. Ltd., for his support and comments, which helped in completing the present research.

\section{REFERENCES}

1) Komura, T., Goda, K., Takahashi, S. and Ozaki, T.: Groundwater drawdown at the tidal gate foundation construction site, Proceedings of VI section of 65th Annual Meeting of the Japanese Society of Civil Engineers, pp. 543-544, 2010 (in Japanese).

2) Ohta, K., Kohno, E. and Takahashi, S.: Groundwater work for the construction of the underground access railway to Sendai Air Port-Super well point method and vacuum press type recharge well, The Foundation Engineering \& Equipment, Vol. 34, No. 3, pp. 55-59, 2006 (in Japanese).

3) Ozaki, T., Yamauchi, D., Shirakawa, T., Chiba, M. and Takahashi, S.: Remediation for the polluted soil by VOCs using strong vacuum, Technical News of the Center of Soil Environment, Geo-Environmental Protection Center, No. 10, pp. 1-6, 2005 (in Japanese).

4) Ozaki, T. and Takahashi, H.: Remediation for soil and groundwater by super well point principle and remediation example, Journal of Civil Engineering, Vol. 53, No. 8, 2012 (in Japanese). 
5) Nakagawa, K., Momii, K., Jinno, K., Wada, S., Park, K. H., Nakayama, H. and Takahashi, S.: Numerical study of groundwater drawdown by super well point method, Proceedings of Spring Conference, Japanese Association of Groundwater Hydrology, pp. 94-97, 2006 (in Japanese).

6) Hosokawa, T., Takahashi, S., Jinno, K., Nakayama, H. and Park, K. H.: Analysis of saturated-unsaturated groundwater seepage flow for the new version of vacuum deep well, Proceedings of Autumn Conference, Japanese Association of Groundwater Hydrology, pp. 84-87, 2006 (in Japanese).

7) Van-Genuchten, M. T.: A closed-form equation for predicting the hydraulic conductivity of unsaturated soils, Soil Science Society of America Journal, Vol. 44, No. 5, pp. 892-898, 1980.

8) Mualem, Y.: A catalogue of the hydraulic properties of unsaturated soils, Hydrodynamics and Hydraulic Laboratory, Israel, 1976.

9) Jinno, K., Momii, K., Fujino, K., Nakagawa, K., Hosokawa, T., Egusa, N. and Hiroshiro, Y.: Numerical Analysis of
Mass Transport in Groundwater, pp. 83-85, Kyushu University Press, 2001 (in Japanese).

10) Matsuo, S. and Kono, I.: Groundwater Lowering Technology, Kajima Publishing, pp. 69-71, 1970 (in Japanese).

11) Kinzelbach, W.: Groundwater Modeling, Elsevier Publishers, Chapter 3, 1986.

12) Bear, J. and Verruijt, A.: Modeling Groundwater Flow and Pollution, D. Reidel Publishing, pp. 225-284, 1987.

13) Fetter, C. W.: Applied Hydrogeology (4th edition), pp. 150-165, 2001.

14) Sato, K. and Iwasa, Y.: Groundwater Hydraulics, Springer, pp. 33-41, 2003.

15) Chenaf, D. and Chapuis, R.: Seepage face height, water table position, and well efficiency at steady state, Ground Water, Vol. 45, No. 2 (March-April), pp. 168-177, 2007.

(Received October 24, 2012) 